\title{
Determinação do Sistema Endócrino Difuso nos Intestinos de Três Teleostei (Pisces) de Água Doce com Hábitos Alimentares Diferentes
}

\author{
José Teixeira de Seixas Filho ${ }^{1,2}$, Cláudio César Fonseca ${ }^{3}$, Maria Goreti de Almeida Oliveira ${ }^{4}$, \\ Juarez Lopes Donzele ${ }^{5}$, Eliane Menin 6
}

\begin{abstract}
RESUMO - O objetivo do presente trabalho foi o de verificar a presença de células endócrinas nos intestinos médio e posterior, ou reto, e nos cecos pilóricos de três espécies tropicais de peixes Teleostei de água doce com hábitos alimentares diferentes: piracanjuba, (Brycon orbignyanus) e piau (Leporinus friderici), onívoro; e surubim (Pseudoplatystoma coruscans), carnívoro. Para tanto, foram utilizados sete exemplares da piracanjuba, com médias de peso e comprimento-padrão de 410,16 $\pm 66,33 \mathrm{~g}$ e $27,42 \pm 1,17 \mathrm{~cm}$, respectivamente, 13 exemplares de piau com médias de 77,71 $\pm 24,31 \mathrm{~g}$ e 14,84 $\pm 1,56 \mathrm{~cm}$ de peso e comprimento-padrão, respectivamente; e cinco exemplares do surubim com médias de peso e comprimento-padrão de 309,91 $\pm 94,23$ g e 32,70 $\pm 1,79$ cm, respectivamente. Podese constatar a presença de células endócrinas do "tipo aberto" nos segmentos referentes aos intestinos médio e posterior das espécies onívoras e do "tipo fechado" no intestino médio e no reto da espécie carnívora. As células argirófilas foram observadas entre as células absortivas do epitélio intestinal. Os resultados permitem concluir que a presença de células endócrinas nas espécies estudadas pode indicar que estas atuam no mecanismo de controle da absorção dos nutrientes do alimento.
\end{abstract}

Palavras-chave: células argirófilas, endocrinologia, hábito alimentar, sistema endócrino difuso, Teleostei tropical

\section{Analysis of the Diffuse Endocrine System in the Intestines of three Freshwater Teleostei (Pisces) with Different Feeding Habits}

\begin{abstract}
The objective of this work was to verify the presence of endocrine cellules in the medium and posterior intestines, or rectum, and in the piloric cecum in three tropical freshwater Teleostei species with different feeding habits: piracanjuba, (Brycon orbignyanus) and piau (Leporinus friderici) omnivorous; and surubim (Pseudoplatystoma coruscans), carnivore. Seven exemplars of piracanjuba, with average weight and standard length of $410.16 \pm 66.33 \mathrm{~g}$ and $27.42 \pm 1.17 \mathrm{~cm}$, respectively, 13 exemplars of piau with average weight and standard length of $77.71 \pm 24.31 \mathrm{~g}$ and $14.84 \pm 1.56 \mathrm{~cm}$, respectively; and five exemplars of surubim with average weight and standard length of $309.91 \pm 94.23 \mathrm{~g}$ and $32.70 \pm 1.79 \mathrm{~cm}$, respectively, were used. The presence of endocrine cellules like "open" was verified on the segments related to the medium and posterior intestines omnivores species and like "closed" in the medium intestine and in the rectum of the carnivore specie. The argirofiles cellules were observed among the as absortive cellules of intestinal epithelium. The results showed that the presence of endocrine cellules can indicate that the studied species act in the absorption control mechanism of food nutrients. However, due to the obtained amounts, more studies are necessary to elucidate this control.
\end{abstract}

Key Words: argirofile cellules, endocrinology, feeding habit, diffused endocrine system, tropical Teleostei

\section{Introdução}

O uso de dieta artificial tem participação significativa nos custos da criação dos organismos aquáticos. Assim, conhecimentos sobre nutrição são imprescindíveis para o sucesso dessa criação, uma vez que minimizarão custos desnecessários ao subsidiarem informações essenciais para a composição desse tipo de alimento. É fundamental intensificar as pesquisas relativas à fisiologia digestiva de peixes, dentre elas as que se direcionam para a estrutura e fisiologia do aparelho digestório, a enzimologia digestiva, o metabolismo e as exigências nutricionais.

As células granulares ou enterocromafins, de localização basal do epitélio apresentam função endócrina. Essas células são caracterizadas pela argentafinidade ou argirofilia. Polak et al. (1993), citados por FONSECA (1996), mencionaram que a atuação dessas células, até o presente, não é totalmente conhecida, nem quais peptídeos apresentam

\footnotetext{
1 Parte da tese de Doutorado do primeiro autor, financiada pelo CNPq e FAPEMIG.

2 Pesquisador da Fund. Inst. de Pesca do Estado do RJ - FIPERJ - Alameda São Boaventura, 770, Fonseca, Niterói, RJ 24120-191. E.mail: seixasfilho@yahoo.com

3 Prof. do Depto de Medicina Veterinária/ UFV, Viçosa - 36570-000, MG.

4 Profa do Depto de Bioq. e Biol. Molecular e BIOAGRO/ UFV, Viçosa - 36570-000, MG.

5 Professor do Depto de Zootecnia/ UFV, Viçosa - 36570.000, MG.

6 Professora do Depto de Biologia Animal/ UFV, Viçosa - 36570.000, MG.
} 
importância fisiológica e o seu papel. Pode-se admitir que células da parte endócrina do sistema nervoso atuem como efetoras, para suportar, modular ou ampliar as ações dos neurônios das outras divisões do sistema nervoso. Os diferentes mecanismos de ação dos peptídeos do sistema endócrino difuso e a sua localização tanto em células nervosas como em células endócrinas são classificados de acordo com três tipos de funções básicas: endócrina, parácrina e neurócrina. A função endócrina é característica dos peptídeos que atuam à distância, através da circulação, enquanto as funções parácrina e neurócrina são geralmente características dos peptídeos de ação local.

Em relação à localização dos grânulos de secreção das células endócrinas, FUJITA e KOBAYASHI (1971) relataram que estes localizam-se na região basal da célula e que esta pode ser denominada "tipo aberto", quando contacta com o lume intestinal por meio de prolongamentos citoplasmáticos, ou "tipo fechado", quando não contacta o lume intestinal.

Fujita e Kobayashi (1973), citados por FONSECA (1996), descreveram que a secreção de hormônios pode ser causada por estímulos físicos, como a distensão da mucosa intestinal após a ingestão do alimento, nas células do "tipo fechado". Segundo esses autores, tanto as células endócrinas do "tipo fechado" quanto as células do "tipo aberto" podem receber informação para a sua atividade secretora por via sangüínea, em adição ao estímulo oriundo do lume intestinal. Relataram, ainda, que o sangue gerador de estímulos adequados deve ser diferente de um tipo celular para o outro, como no caso do estímulo luminal.

A partir do isolamento de peptídeos da mucosa gastrintestinal e do pâncreas de algumas espécies de mamíferos (LARSSON et al., 1975; LARSSON e JÆRGENSEN, 1978; ITO e KOBAIASHI, 1976; REDDY et al., 1985; FURUKAWA et al., 1986), muitos estudos imunocitoquímicos, envolvendo células endócrinas gastroenteropancreáticas, têm sido realizados. Apesar disso, existem poucos dados quantitativos disponíveis sobre esses tipos celulares nas diferentes espécies animais (SILVA, 1992).

Outros autores (ERSPAMER, 1954, 1958; GABE e MARTOJA, 1971, 1972; Van NOORDEN et al., 1972; GABE, 1973; Van NOORDEN e PEARSE, 1974; ÖSTBERG et al., 1976) observaram células argirófilas em várias espécies de peixes. Células argentafins foram encontradas em alguns Teleostei, como em Anguilla occidentallis australlis, Salmo trutta e Salmo irideus (READ e BURNSTOCK, 1968) e Mugil auratus (GABE e MARTOJA, 1971).

Esses achados, associados a métodos bioquímicos, que detectaram vários entero-hormônios (secretina, colecistoquinina-pancreazimina, somatostatina) no intestino de Teleostei (NILSSON, 1970; BARRINGTON e DOCKRAY, 1972; DOCKRAY, 1974, 1975; LEE e CHIN, 1996; REINEEKE et al., 1997), sugerem que diferentes tipos de células enteroendócrinas podem estar presentes no tubo digestório desses peixes.

O objetivo deste trabalho foi verificar a presença de células endócrinas nos intestinos médio e posterior, ou reto, e nos cecos pilóricos, em três espécies tropicais de peixes Teleostei de água doce com hábitos alimentares diferentes: piracanjuba (Brycon orbignyanus) e piau (Leporinus friderici), onívoros; e surubim (Pseudoplatystoma coruscans), carnívoro.

\section{Material e Métodos}

Foram utilizados sete exemplares da piracanjuba (Brycon orbignyanus Valenciennes, 1849) (Characiformes, Characidae, Bryconinae), com médias de peso e comprimento-padrão de 410,16 $\pm 66,33 \mathrm{~g} \mathrm{e}$ $27,42 \pm 1,17 \mathrm{~cm}$, respectivamente; 13 exemplares de piau (Leporinus friderici, Bloch, 1794) (Characiformes, Anostomidae), com médias de 77,71 $\pm 24,31 \mathrm{~g}$ e 14,84 \pm $1,56 \mathrm{~cm}$ de peso e comprimento-padrão, respectivamente; e cinco exemplares do surubim (Pseudoplatystoma coruscans Agassiz, 1829) (Siluriformes, Siluroidei, Pimelodidae), com médias de peso e comprimentopadrão de $309,91 \pm 94,23 \mathrm{~g}$ e $32,70 \pm 1,79 \mathrm{~cm}$, respectivamente, procedentes da Estação de Pesquisas e Desenvolvimento Ambiental de Volta Grande, CEMIG, em Conceição das Alagoas, MG.

Os animais foram coletados com auxílio de tarrafas e redes de arrasto. Em seguida, foram transportados em sacos plásticos com oxigenação, em caixas de isopor, até o laboratório e, então, acondicionados em aquários com capacidade para 200 litros, abastecidos com água corrente, sendo então submetidos a jejum, durante 72 horas. Após esse período, os exemplares foram isolados e preparados, para o processamento histológico.

A rotina para isolamento, identificação e fixação do tubo digestório foi: a) secção transversal da medula espinhal imediatamente após a região occipital do exemplar; b) obtenção do comprimento-padrão do exemplar, conforme RICKER (1968); c) pesagem do exemplar; d) isolamento do tubo digestório, por meio de 
secção transversal do esôfago, caudalmente ao septo transverso, e do intestino posterior, cranialmente ao ânus; e) limpeza do tubo digestório, por meio de passagem de solução fisiológica para peixes Teleostei (HOAR e HICKMAN, 1967) através da luz deste tubo digestório, para melhor preservação da mucosa; e f) identificação do tubo digestivo e imersão no líquido de Bouin, durante 12 a 24 horas, à temperatura ambiente.

O preparo dos intestinos médio, posterior, reto e cecos pilóricos foi feito através de distensão e secções transversais seriadas, das quais foram obtidos fragmentos de $1,0 \mathrm{~cm}$ de comprimento, identificados com números crescentes em sentido caudal (MENIN, 1988).

\section{Processamento e análise do material}

O processamento histológico das peças foi realizado no Laboratório de Histopatologia do Departamento de Medicina Veterinária, do Centro de Ciências Biológicas e da Saúde da UFV. Para o estudo histológico, as peças foram desidratadas em séries crescentes de álcool etílico, clarificadas com xilol e incluídas em parafina, segundo as técnicas de rotina (HUMASON, 1972). Durante a inclusão em parafina, os fragmentos intestinais foram orientados para cortes transversais. Os cortes seriados, de $5 \mathrm{~mm}$ de espessura, obtidos com o auxílio de micrótomo Spencer, foram submetidos às técnicas de rotina de desparafinização, hidratação e coloração (HUMASON, 1972).

Para a identificação das células argirófilas, os intestinos e os cecos pilóricos foram submetidos à técnica de coloração histoquímica de impregnação pela prata (GRIMELIUS, 1968), com a finalidade de verificar a distribuição e quantificação destas células nos diferentes segmentos dos intestinos médio, posterior (ou reto) e cecos pilóricos.

\section{Método de Grimelius (GRIMELIUS, 1968)}

a) Lavagem da vidraria por 60 minutos em água corrente, seguida de dois a três banhos em água destilada obtida em destilador de vidro, b) Desparafinização das lâminas em xilol (dois banhos de 15 min cada), c) Hidratação na série decrescente de álcoois absolutos, 95, 80 e 70\% (3 min em cada), d) Hidratação em água comum e em água destilada em vidro (5 min em cada), e) Incubação das lâminas em solução de $80 \mathrm{mg}$ de $\mathrm{AgNO}_{3}$, em tampão acetato $0,02 \mathrm{M}$ a $60^{\circ} \mathrm{C}$, por três horas, f) Revelação em solução de hidroquinona ( $1 \mathrm{~g})$, sulfito de sódio (5 g) e $100 \mathrm{~mL}$ de água destilada em vidro $(100 \mathrm{~mL})$, por 30 segundos, g) Interrupção da revelação em água destilada em vidro, h) Desidratação na série crescente de álcoois $70,80,95 \%$ e absoluto I (30 seg. em cada) e absoluto II (60 seg.), I) Diafanização em xilol I e II, rapidamente, J) Montagem das lâminas e lamínulas com Bálsamo de Canadá.

Para coloração de Grimellius, utilizou-se controle positivo previamente testado (intestino delgado de gambá adulto), incluído em cada bateria de coloração (FONSECA, 1996).

\section{Fotomicrografias}

As fotomicrografias utilizadas na documentação das descrições histológicas foram realizadas no Laboratório Fotográfico do Setor de Anatomia Vegetal do Departamento de Biologia Vegetal do CCB, UFV, com auxílio de microscópio óptico binocular. As pranchas histológicas das espécies em estudo foram feitas com auxílio de microcomputador, por meio de digitalização das fotos no programa PHOTO SHOP 4.0, e a diagramação foi realizada no programa POWER POINT.

\section{Resultados e Discussão}

Verificou-se, à luz da microscopia óptica, a presença de células endócrinas nos segmentos referentes aos intestinos médio e posterior das espécies onívoras, piracanjuba e piau, e ao intestino médio e ao reto da espécie carnívora, surubim corados pela técnica de GRIMELIUS (1968). As células argirófilas foram observadas entre as células absortivas, principal constituinte do epitélio intestinal para essas espécies de Teleostei, concentradas na base do epitélio (Figura 1).

Em relação à quantidade das células endócrinas, foram identificadas raras células argirófilas nos intestinos médio e posterior, ou reto, nas três espécies estudadas. Entretanto, não foi verificada a presença dessas células nos cecos pilóricos das espécies onívoras em estudo (Tabela 1).

Quanto às características morfológicas das células endócrinas encontradas no epitélio intestinal desses Teleostei, pode-se comprovar, para as três espécies, a presença de grânulos no interior da célula, cujo conteúdo, contendo a prata, foi revelado na presença de hidroquinona-sulfito de sódio, tornando-se visível. Estas células foram identificadas como sendo do "tipo aberto", para as espécies onívoras, piracanjuba e piau, uma vez que se pôde observar o prolongamento citoplasmático em direção ao lume intestinal (Figura 1). Na espécie carnívora, surubim, as células argirófilas 

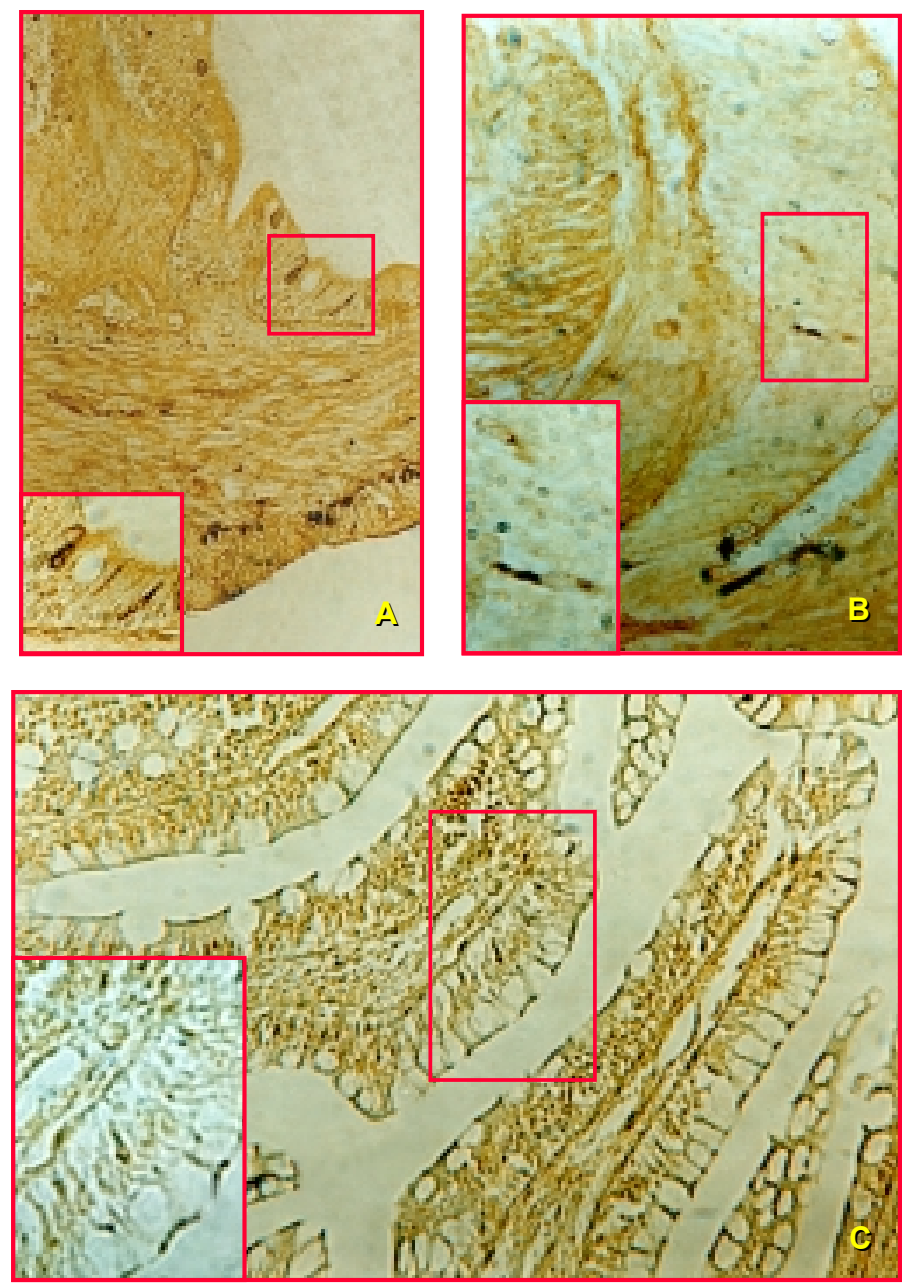

Figura 1 - Células argirófilas nos intestinos médio e posterior de Leporinus friderici, aumento: 250x e 390x no detalhe (A), e Brycon orbignyanus, aumento: 500x e 780x no detalhe (B), e intestino médio e reto de Pseudoplatystoma coruscans, aumento: 312x e 780x no detalhe (C).

Figure 1 - Argirofile endocrine cellules in the medium and posterior intestines of Leporinus friderici, increase: 250x and $390 x$ in the detail $(A)$ and Brycon orbignyanus, increase: $500 x$ and $780 x$ in the detail $(B)$ and medium intestine and rectum of Pseudoplatystoma coruscans, increase: $312 x$ e $780 x$ in the detail (C). observadas foram do "tipo fechado", uma vez que estas se encontravam confinadas na região basal da mucosa intestinal, sem contato com o lume intestinal, recobertas pelas células do epitélio.

A presença de células endócrinas argirófilas nos intestinos médio e posterior, nas espécies onívoras, piracanjuba e piau, e no intestino médio e reto, na espécie carnívora, surubim, confirma as observações de outros autores (ERSPAMER, 1954, 1958; GABE e MARTOJA, 1971, 1972; Van NOORDEN et al.,1972; GABE, 1973; Van NOORDEN e PEARSE, 1974; ÖSTBERG et al., 1976; ROUMBOUT, 1977, 1986; GARCIA HERNANDEZ et al., 1994; REINEEKE et al., 1997), que encontraram essas células em várias espécies de peixes Teleostei.

Utilizando-se técnicas histológicas e imunocitoquímicas, em diferentes espécies de peixes Teleostei, alguns autores chamaram a atenção para a substancial diferença na distribuição dessas células no tubo digestivo (ROUMBOUT, 1977, 1986; L'HERMITE et al., 1985; GARCIA HERNANDEZ et al., 1994). No presente estudo, em razão da pouca quantidade de células argirófilas encontradas tanto no intestino médio como no intestino posterior (ou reto), foi incluído em cada bateria de coloração controle previamente testado de intestino de gambá adulto. L'HERMITE et al. (1985), quando estudaram, em Anguilla anguilla, a presença de células endócrinas no sistema gastroenteropancreático, também encontraram raras células argirófilas. Por outro lado, ROMBOUT (1977), trabalhando com Barbus conchonius, relatou alta percentagem de células endócrinas, $3 \%$ em relação às células epiteliais, na primeira parte do intestino médio, ocorrendo redução em direção à porção caudal do intestino posterior.

GARCIA HERNÁNDEZ et al. (1994), quando estudaram a ontogenia das células endócrina do tubo

Tabela 1 - Células endócrinas argirófilas nos intestinos médio e posterior e cecos pilóricos da piracanjuba (Brycon orbignyanus) e do piau (Leporinus friderici) e no intestino médio e reto do surubim (Pseudoplatystoma coruscans)

Table 1 - Argirofile endocrine cellules in the medium and posterior intestines and piloric cecum of piracanjuba (Brycon orbignyanus) e do piau (Leporinus friderici) and in the medium intestine and rectum of surubim (Pseudoplatystoma coruscans)

\begin{tabular}{lcccc}
\hline $\begin{array}{l}\text { Espécie } \\
\text { Specie }\end{array}$ & $\begin{array}{c}\text { Intestino médio } \\
\text { Posteriorintestine }\end{array}$ & $\begin{array}{c}\text { Intestino posterior } \\
\text { Posteriorintestine }\end{array}$ & $\begin{array}{c}\text { Reto } \\
\text { Rectum }\end{array}$ & $\begin{array}{c}\text { Cecos pilóricos } \\
\text { Piloric cecum }\end{array}$ \\
\hline Piracanjuba & \pm & \pm & $\mathrm{np}$ & - \\
Piau & \pm & \pm & $\mathrm{np}$ & - \\
Surubim & \pm & $\mathrm{np}$ & \pm & $\mathrm{np}$ \\
\hline
\end{tabular}

- = negativo; \pm = raras; $\mathrm{np}=$ não possui.

- = negative; \pm = rare; $n p=$ absence.

Rev. bras. zootec., 30(5):1403-1408, 2001 
digestório de Dicentrarchus labrax, comentaram que, embora o número de células endócrinas, aparentemente, tenha aumentado durante o desenvolvimento do tubo digestório, na fase de larva deste Teleostei estas foram escassas aos 61 dias de idade. Larsson (1977), Lehy e Cristina (1979) e Tagliafierro et al. (1989), citados por GARCIA HERNANDEZ et al. (1994), ressaltaram que o número de células endócrinas aumenta durante o desenvolvimento embrionário, sendo mais numeroso nos últimos estágios de desenvolvimento que nos adultos.

No presente estudo pôde-se observar que as células endócrinas encontravam-se dispostas entre as células absortivas, preferencialmente na região basal do epitélio dos intestinos médio e posterior (ou reto) das espécies em estudo, sendo esta posição similar à encontrada em outras espécies de peixes Teleostei por ROUMBOUT (1977), em Barbus conchonius, L'HERMITE et al. (1985), em Anguilla anguilla, GARCIA HERNANDEZ et al. (1994), em Dicentrarchus labrax, e REINEEKE et al. (1997), em Scuphthalmus maximus.

As células argirófilas dos segmentos intestinais, das espécies onívoras estudadas, foram identificadas como sendo "tipo aberto", uma vez que se pôde observar seu prolongamento citoplasmático em direção ao lume intestinal. Este tipo de célula, provavelmente, pode ser um receptor-sensorial, recebendo informações químicas específicas em seu ápice, provenientes do lume intestinal, que estimulam ou inibem as secreções na base celular, conforme mencionado por FUJITA e KOBAYASHI (1974). Já as células argirófilas do intestino médio e do reto, na espécie carnívora, observadas neste trabalho, são do "tipo fechado", não estando aptas a receber tais estímulos, porque encontram-se separadas do lume intestinal por uma camada de células epiteliais.

A ausência de células argirófilas nos cecos pilóricos das espécies onívoras estudadas é um achado que indica a necessidade de estudos futuros, visando elucidar o mecanismo do controle de absorção nessas espécies, uma vez que, apesar da observação de raras células no intestino médio, os cecos pilóricos são prolongamentos da sua mucosa. Por outro lado, BEORLEGUI et al. (1992) observaram numerosas células endócrinas nos cecos pilóricos e no intestino da truta arco-íris, Oncorhynchus mykiss, imunorreativas a um grande número de pepetídeos regulatórios.

LARSSON e JØRGENSEN (1978) relataram que o tubo digestório de ratos e humanos contêm numerosas células endócrinas produzindo hormônios peptídeos que participam na regulação da digestão, absorção e utilização de nutrientes.
A presença de células endócrinas nos segmentos intestinais, das espécies em estudo, pode indicar que estas possuem algum controle fisiológico, tornandose necessários estudos futuros para elucidá-lo.

\section{Conclusões}

Verificou-se a presença de células endócrinas nos segmentos referentes aos intestinos médio e posterior das espécies onívoras e no intestino médio e no reto da espécie carnívora.

As células argirófilas foram observadas entre as células absortivas, principal constituinte do epitélio intestinal para essas espécies de Teleostei, concentradas na base do epitélio.

Em relação à quantidade das células endócrinas, raras células argirófilas foram identificadas nos intestinos médio e posterior, ou reto, nas três espécies estudadas. Não foi verificada a presença dessas células nos cecos pilóricos das espécies onívoras em estudo.

Quanto às características morfológicas das células endócrinas pode-se comprovar, para as três espécies, a presença de grânulos no interior da célula, contendo sais de prata que foram reduzidos em presença de Hidroquinona, tornando-se visíveis.

Estas células foram identificadas como do "tipo aberto" para as espécies onívoras, piracanjuba e piau. Na espécie carnívora, surubim, as células argirófilas observadas foram do "tipo fechado".

A ausência de células argirófilas nos cecos pilóricos das espécies onívoras estudadas é um achado que indica a necessidade de estudos futuros, uma vez que, apesar da observação de raras células no intestino médio, os cecos pilóricos são prolongamentos da sua mucosa.

Os resultados relativos à presença de células endócrinas nas espécies estudadas permitem concluir que estas atuam no mecanismo de controle da absorção dos nutrientes do alimento.

\section{Referências Bibliográficas}

BARRINGTON, E.J.W., DOCKRAY, G.J. 1972. Cholecystokininpancreozimin like activity in the eel (Anguilla anguilla). Gen. Comp. Endocrinol., 19:80-87.

BeORLEGUi, C., MARTINEZ, A., SESMA, P. 1992. Some peptide-like colocalizations in endocrine cells of the pyloric caeco and the intestine of Oncohrynchus myskiss (Teleostei). Cell Tissue Res., 269:353-357.

DOCKRAY, G.J. 1975. Comparative studies on secretin. Gen. Comp. Endocr., 25:203-210.

DOCKRAY, G.J. 1974. Extration of a secretin-like factor from the intestines of pike (Esos lucius). Gen. Comp. Endocri., 23:340-347.

DOCKRAY, G.J. 1976. Immunochemical evidence chlecystokinin-like peptides in brain. Nature, 264:568-570. 
ERSPAMER, V. 1954. Pharmacology of indolealkylamines. Pharmacol., 6:425-487.

ERSPAMER, V. Occurence and distribution of 5-hydroxytryptamine (enteramine) in the living organism. Z Vitamin-Hormon u Fermentforsch., 9:74-96. 1958.

FONSECA, C.C. Identificação imunocitoquímica e ultraestrutural das células produtoras de glucagon no pâncreas e nas mucosas do corpo do estômago, do íleo e do cólon durante o desenvolvimento do gambá Didelphis albiventris, Lund, 1841 (Marsupialia). Belo Horizonte, MG: UFMG, 1996. 180p. Dissertação (Doutorado em Morfologia Animal) - Universidade Federal de Minas Gerais, 1996.

FUJITA, T., KOBAYASHI, S. 1971. Experimentally induced granules release in the enteroendocrine cells of dog pyloric antrum. Z. Zellforch, 116:52-60.

FUJITA, T., KOBAYASHI, S. 1974. The cells and hormones of the GEP-endocrine system. The current studies. In: FUJITA, T. (Ed.). Gastro-entero-pancreatic system. a cell-biological approach. Stuttgart. p.1-16.

FURUKAWA, F., TOYODA, K., HASEGAWA, R. et al. 1986. Immunohistochemical localization of pancreatic endocrine cells in the hamster. Bull. Natl. Inst. Hyg. Sci., 104:77-82.

GABE, M., MARTOJA, M. 1972. Contribution a l'histologie des cellules endocrines gastriques des selaciens. Arch. Anat. Micr. Morph. Exp., 61:17-32.

GABE, M. 1973. Données histologiques sur le stratum compactum intestinal deSalmo gairdneri irideus Gibb. (Teleosteen, Salmonidae). Ann. Sci. Nat. Zool. Biol. Anim., 15(1):11-26.

GABE, M., MARTOJA, M. 1971. Dneés histologiques sur le cellules endocrines gastriques et pancreatiques de Mugil auratus (Téléostéi - Mugiliforme). Arch. Anat. Micr. Morph. Exp., 60:219-234.

GARCIA HERNANDEZ, M.P., LOZANO, M.T., AGULLEIRO, A. 1994. Ontogeny of some endocrine cells in the digestive tract in the sea bass (Dicentrarchus labrax). An immunocytochemical study. Cell Tissue Res., 277:373-383.

GAS, N., NOAILLAC-DEPEYRE, J. 1981. Organization, ultrastructure et fonction du tube digestif des Téléostéens d'eau douce. In: FONTAINE, M. (Ed.) Nutrition des Poissons. Paris: Editions du Centre National de la Recherche Scientifique. p.20-44.

GRIMELIUS, L. 1968. A silver nitrate stain for cells in human pancreatic islet. Act. Soc. Med. Ups., 73:243-270.

HOAR, W.S., HICKMAN JR., C.P. 1967. General and comparative physiology. New Jersey, Prentice-Hall. 296p.

HUMASON, G.L. 1972. Animal tissue techniques. 3.ed. São Francisco: W.H. Freeman and Company. 641p.

ITO, S., KOBAYASHI, S. 1976. Immunocytochemical demostration of glucagon and GLI containing cells in the canine gut and pancreas. Arch. Histol. Jap., 39:193-202.

LARSSON, L.I., HOLST, J., HAKANSON, R. et al. 1975. Distribution and porperties of glucagon immunoreactivity in digestive tract of various mammals: An immunohistochemical and immunochemical study. Histochemistry, 44:281-290.

LARSSON, L.I., JØRGENSEN, L.M. 1978. Ultrastructural and cytochemical studies on the cytodifferentiation of duodenal endocrine cells. Cell Tiss. Res., 194:79-102.

LEE, J.S., CHIN, P. 1996. Uptake of polysaccharide with development of alimentary tract in embryo of Ditrematemmincki (Teleostei. Embiotocidae). J. Korean Fish. Soc., 39:430-440.
L'HERMITE, A., FERRAND, R.DUBOIS, M.P. 1985. Detection of endocrine cells by immunofluorescence method in the gastroenteropancreatic system of the adult ell, glass-eel, and Leptocephalic larva (Anguilla anguilla L.). General and Comparative Endocrinology, 58:347-359.

MENIN, E. Anátomo-histologia funcional comparativa do aparelho digestivo de seis Teleostei (Pisces) de água doce. São Paulo: USP, 1988.557p. Tese (Doutorado) - Universidade de São Paulo, 1988.

NILSSON, A. Gastrointestinal hormones in the holocephalian fish, Chimacra monstrosa (L.). Comp. Biochem. Physiol., 32:387-390, 1970.

ÖSTBERG, Y., Van NOORDEN, S., PEARSE, A.G.E. et al. 1976. Cytochemical immunofluorescence and ultrastructural investigations on polypeptide hormone containing cells in the intestinal mucosa of a cyclostome, Myxime glutinosa. Gen. Comp. Endocr., 28:213-227.

READ, J.B., BURNSTOCK, G. 1968. Fluorescent histochemical studies on the mucosa of the vertebrate gastrointestinal tract. Histochemic F, 324-332.

REDDY, S.N., BIBBY, N.J., ELLIOT, R.B. 1985. Cellular distribuition of insulin, glucagon, pancreatic polipeptide and somatostatin in the fetal and adult pancreas of the guinea-pig: a comparative immunohistovhemical study. Eur. J. Cell. Biol., 38:301-305.

REINEEKE, M., MULlER, C., SEGNER, H. 1997. An immunohistochemical analysis of the ontogeny, distribuition and coexistence of 12 regulatory peptides and serotonin in endocrine cells and nerve fibers of the digestive tract of the turbot, Scophthalmus maximus (Teleostei). Anatomy and embriology, 105:87-101.

RICKER, W.E. 1968. Methods for assessment of fish production in fresh waters. Oxford: Blackwell Scientific Publications, 313p.

ROMBOUT, J.H.W.M. 1977. Enteroendocrine cells in the digestive tract of Barbus conchonius (Teleostei, Cyprinidae). Cell Tissue Res., 185: 435-450.

ROMBOUT, J.H.W.M., Van der GRINTEN, G.P.M., PEEZEBINK HORT, F.M. et al. 1986. Immunocytochemical identification and localization of peptides hormones in the gastro-entero-pancreatic (GEP) endocrine system of the mouse and a stomachless fish, Barbus conchonius. Histochemistry, 84:471-483.

SILVA, J.C.P. Estudo quantitativo das células argirófilas, argentafins e $G$ do estômago e níveis séricos e teciduais da gastrina em suínos com e sem úlcera gástrica. Belo Horizonte, MG: UFMG, 1992. 105p. Dissertação (Doutorado em Zootecnia) - Universidade Federal de Minas Gerais, 1992.

Van NOORDEN, S., GREENBERG, J., PEARSE, A.G.E. 1972. Cytochemical and immunofluorescence investigations on polypeptide hormone localizations in the pancreas and gut oflarval Lamprey. Gen. Comp. Endocr., 19:192-199.

Van NOORDEN, S., PEARSE, A.G.E. 1974. Immunoreactive polypeptide hormones in the pancreas and gut of the Lamprey. Gen. Comp. Endocr., 23: 311-324.
Recebido em: 27/09/00 Aceito em: 29/03/01 